\title{
A study of the scour-fill threshold based on Lane's equilibrium relation: The lower Yellow River
}

\author{
Jiongxin Xu \\ Institute of Geographic Sciences and Natural Resources Research, Key Laboratory for Water Cycle and Land Surface Processes, Chinese Academy of Sciences, Beijing 100101, China
}

\section{A R T I C L E I N F O}

\section{Article history:}

Received 4 March 2015

Received in revised form 11 August 2015

Accepted 18 August 2015

Available online 24 August 2015

\section{Keywords:}

Scour-fill threshold

Lane's relation

Channel sediment delivery ratio

Lower Yellow River

\begin{abstract}
A B S T R A C T
The scour-fill threshold in river channels is an expression of scour-fill equilibrium, which may be understood as the balance between the river's sediment carrying capability and the sediment load imposed by the drainage basin. In the present study, the above capability-load relation is quantified using Lane's relation, $\gamma Q J-Q_{s} D_{50}$, wherein $Q$ is water discharge, $J$ is channel slope, $Q_{s}$ is sediment transport rate, $D_{50}$ is median size of bed material, and $\gamma$ is the specific weight of water. On this basis, we have established scour-fill thresholds for the lower Yellow River based on data from 141 flood events. The results show that the $Q_{s} D_{50}-\gamma Q J$ relation may well distinguish between the scour and fill flood events. The following equation has been established: $\operatorname{SDR}_{\mathrm{FE}}=0.00099(\gamma Q J)^{0.90}\left(Q_{s} D_{50}\right)^{-0.60}$, wherein $\mathrm{SDR}_{\mathrm{FE}}$ is channel sediment delivery ratio. From the equation, the scour-fill threshold is established as: $Q_{s} D_{50}=0.00001(\gamma Q J)^{1.5}$. Starting from this formula, four possible options are proposed for sediment management of the lower Yellow River.
\end{abstract}

(C) 2015 Elsevier B.V. All rights reserved.

\section{Introduction}

The scour-fill threshold in a river channel is an expression of scourfill equilibrium. It may be defined in two ways: a mechanical equilibrium (all the sediment particles composing the channel boundary are at the threshold of entrainment), and a sediment transport equilibrium (the river's sediment carrying capability equals the amount of bed-material sediment supplied from the drainage basin) (Chien et al., 1987). The former is related to the particle-scale and the latter to the river-reach scale. The mechanical equilibrium may be investigated by flume experiments and many results have been published (e.g., Leopold et al., 1964; Schumm, 1977; Chien and Wan, 1983; Knighton, 1998). In natural sand-bedded rivers where the flow conditions vary markedly downstream and with time, study based on the mechanical equilibrium is difficult, while studies based on sediment transport equilibrium are common. In the present study, the fill-scour equilibrium is regarded as the balance between the river's sediment carrying capability and the sediment load imposed by the drainage basin. River geomorphic thresholds, including the scour-fill threshold, define significant changes in processes and morphology and are set by the conditions that govern river channel process and form, among which the most important are the flow regime, the quantity and grain size of sediment delivered to the channel, and the gradient of the channel (Church, 2002). These conditions were well expressed by Lane in his classic paper, published in 1955 (Lane, 1955), in which he presented the qualitative relation:

E-mail address: xujx@igsnrr.ac.cn.
$Q_{S} / \mathrm{Q}-J / D$, wherein $Q$ is water discharge, $J$ is channel slope, $Q_{S}$ is sediment transport rate, and $D$ is the representative sediment grain size. In the present study we use the median size $\left(D_{50}\right)$ as $D$. Slight rearrangement yields the expression $Q_{s} D_{50}-Q J$.

Bull (1979) discussed thresholds and equilibrium between erosion and aggradation using the ratio of stream power to critical power. Stream power $(\gamma Q J)$ multiplied by an efficiency factor of 0.01 (Bagnold, 1966) is the power available to transport sediment, and critical power is the power needed to transport the actual sediment load. The threshold of critical power is related to the condition in which the ratio equals 1.0. When the ratio is $>1.0$, erosion (scour) occurs; when it is $<1.0$, aggradation (fill) occurs. The power needed to transport sediment depends on $Q_{S}$ and $D$ and therefore the product of them. Hence, based on the discussion by Bull (1979), it is reasonable to express the scour-fill threshold using the $Q_{s} D_{50}-\gamma O J$ relation, which is also Lane's relation. Starting from Lane's relation, we will establish the scour-fill threshold based on data from for the lower Yellow River (LYR).

'Threshold' is an important concept in fluvial geomorphology (Schumm, 1977). Using this concept and various methodologies, many results have been achieved (e.g., Schumm, 1977; Vandaele et al., 1996; Tucker, 2004; Xu, 2004, 2005; Phillips, 2006; Binnie et al., 2007; Harnischmacher, 2007). In the LYR, studies have been made on channel scour-fill thresholds by establishing statistical relations between channel sedimentation (or sediment delivery ratio) and sediment concentration $(C)$ (or the index $C / Q$ known as the incoming sediment coefficient) (Zhao, 1996; Zhao et al., 1998; $\mathrm{Xu}, 2003,2014)$. However, most of the published empirical relations fail to express the physical mechanism controlling the scour-fill threshold. 
To harness the Yellow River, where serious sedimentation has caused an increasing threat to flood protection, the first objective is to reduce channel sedimentation and therefore diminish the rise of the bed (Chien and Zhou, 1965; Ye, 1994). After the Xiolangdi dam was built in 1999, a new strategy based on flow and sediment regulation has been put into practice since 2002. Through the regulation of Xiaolangdi and other reservoirs in the Yellow River basin, the engineers attempt to form some optimal flow-sediment combinations for the planned floods released through the Xiaolangdi dam, which may transport the sediment more effectively to the sea and at the same time reform the channel to increase its flood-conveying capacity (Yellow River Institute of Hydraulic Engineering and Water Resources Research, 2010). Determination of scour-fill thresholds is crucial for realizing the objective and important both in science and in engineering practice. The purpose of the present study is to establish a new scourfill threshold relation based on Lane's relation, by which we provide some reference for the practice of flow-sediment regulation in the LYR.

\section{Study area}

The studied reach is the LYR (Fig. 1A) from Mengjin to Lijin, $764 \mathrm{~km}$ in length. The LYR is famous for serious channel sedimentation. In the 1950s, before the Sanmenxia dam construction, 1.6 billion $t$ of sediment was input annually, of which 0.4 billion $t$ was deposited on the bed, causing it to rise at an annual rate of $6-10 \mathrm{~cm} / \mathrm{y}$ continuously. As a result, a hanging (or suspended) channel bed formed, meaning that the bed is higher than the ground surface behind the two artificial levees. Basically no tributaries join the LYR except the Yiluohe, Qinhe, and Dawenhe Rivers. The flow and sediment from the Yiluohe and Qinhe are not much, and those from the Dawenhe are negligibly little. Hence, the LYR is like a great, natural experimental water flume and an ideal environment to study channel scour-fill processes. In 1960, the Sanmenxia dam was built, controlling the flow and sediment input to the LYR. Since 1999, when the Xiaolangdi dam was built 130 downstream from the Sanmenxia dam, it controls the flow and sediment input to the LYR in place of Sanmenxia. For more details of the study area, refer to Xu (2014).

\section{Method and data source}

The scour-fill threshold is the critical point at which scour becomes fill. The approach of the sediment budget (Walling, 1983) related to the whole drainage basin may also be applied to a river reach (Kesel et al., 1992; McLean and Church, 1999; Xu, 2002, 2003; Hassan et al., 2010, 2011) and, accordingly, the sedimentation and sediment delivery ratio (SDR) can be calculated. At reach scales, the scour-fill threshold can be defined using the SDR $(\mathrm{Xu}, 2003,2014)$ : when the SDR is $>1$, scour occurs; when the SDR is $<1$, fill occurs. When SDR is equal to 1 , the reach is considered in a no-scour, no-fill state, which may be expressed by Lane's relation, $Q J-Q_{s} D_{50}$. The left side reflects the river "force" in the reach or the sediment carrying capability and the right the "load" of the reach or the sediment amount imposed from the drainage basin. $Q J$ on the right side may be replaced by $\Omega=\gamma Q \mathrm{~J}$, wherein $\gamma$ is the unit weight of water and $\Omega$ is stream power, or the expenditure of potential energy per unit river length, reflecting the river "force" in the reach to carry the "load". Given the magnitude of $Q_{s}$, the river's energy expenditure needed to carry coarser sediments is more than that needed to carry fine sediments (Chien and Wan, 1983). Therefore, expressing the river's "load" by $Q_{s} D_{50}$ is more reasonable than by $Q_{s}$ alone. The present study follows two steps: first, to establish the regression equation in the form of $\operatorname{SDR}=\mathrm{a}(\gamma Q J)^{\mathrm{b}}\left(Q_{s} D_{50}\right)^{\mathrm{c}}$; then, let SDR $=1$ to establish the

(A)

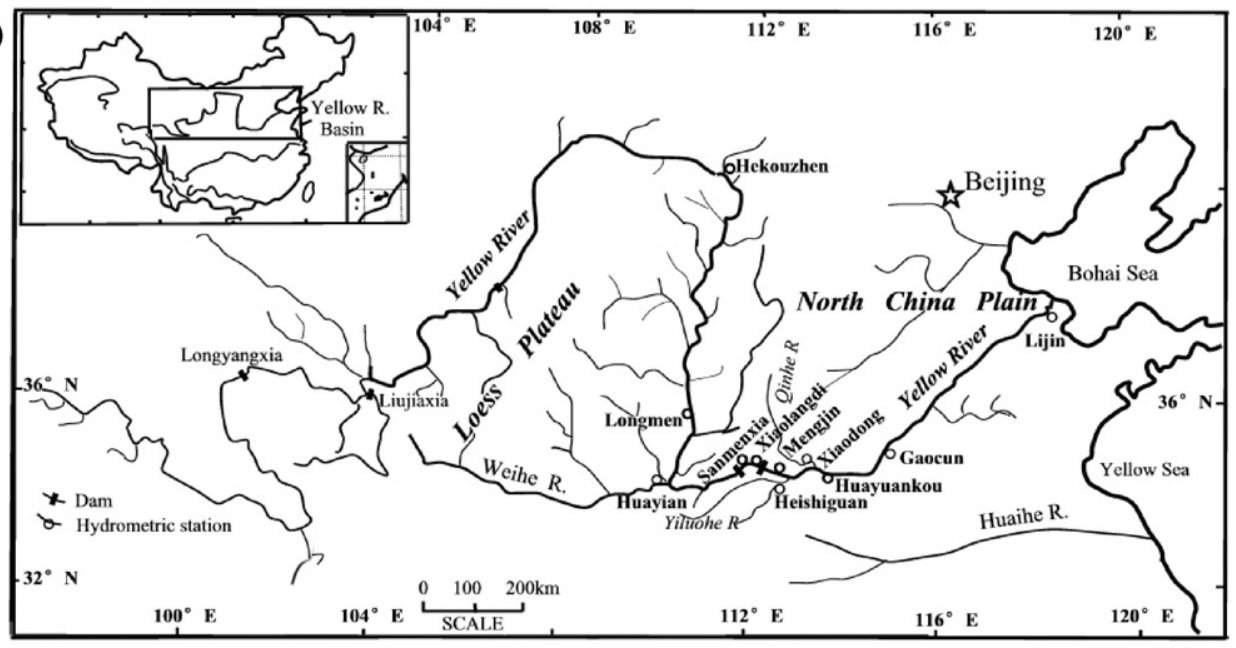

(B)

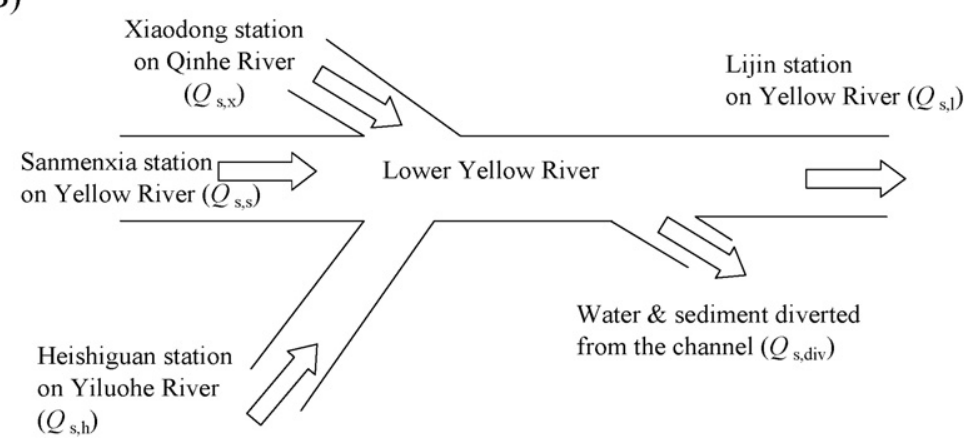

Fig. 1. (A) Study area (modified from Xu (2014)); (B) Diagram showing the input/output relation in the LYR (modified from Xu, 2014). 
expression of the scour-fill threshold. To conduct the statistical analysis, the software package Statistica 5.0 was used.

To obtain data of channel sedimentation during a flood event, the sediment budget at reach scale is used. For the LYR, the components of the sediment budget are shown in Fig. 1B, based on which the following is written:

$S_{\mathrm{dep},[\mathrm{S}-\mathrm{L}]}=\Sigma[$ sediment input $]-\Sigma[$ Sediment output $]$

$$
=\left(Q_{s, s}+Q_{s, \mathrm{~h}}+Q_{s, \mathrm{x}}-Q_{s, \operatorname{div}}\right)-Q_{s, 1}
$$

wherein $S_{\mathrm{dep},[\mathrm{S}-\mathrm{L}]}$ is sedimentation in the river reach from Sanmenxia to Lijin, $Q_{s, s}$ and $Q_{s, 1}$ are suspended sediment load (SSL) at Sanmenxia station and Lijin station on the Yellow River, $Q_{s, \mathrm{~h}}$ is SSL at Heishiguan station on the Yiluohe River, $Q_{s, x}$ is SSL at Xiaodong station on the Yiluohe River, and $Q_{s, \text { div }}$ is the amount of suspended sediment diverted with irrigation water. Eq. (1) is based on data of input and output of SSL and thus, the calculated sedimentation is the total, including that in the main channel and on the floodplain, and no differentiation is made between the two parts. Note that $S_{\text {dep }}$ includes fill and scour; positive $S_{\text {dep }}$ means fill and negative $S_{\text {dep }}$ means scour (Xu, 2014). The SDR of the LYR is defined as:

$\mathrm{SDR}_{[\mathrm{S}-\mathrm{L}]}=[$ Sediment output $] /[$ Sediment input $]$

$$
=Q_{s, 1} /\left(Q_{s, \mathrm{~s}}+Q_{s, \mathrm{~h}}+Q_{s, \mathrm{x}}-Q_{s, \mathrm{div}}\right) \text {. }
$$

$S_{\text {dep,[S-L] }}$ and $\mathrm{SDR}_{[\mathrm{S}-\mathrm{L}]}$ may be calculated either on the basis of flood events or on the basis of annual series data. In the present study, $S_{\mathrm{dep}, \mathrm{FE}}$ and SDR $_{\mathrm{FE}}$ are referred to as $S_{\mathrm{dep}}$ and SDR for flood events. The SSL data used in Eqs. (1) and (2) were collected at the above-mentioned hydrometric stations. The data of $Q_{s, d i v}$ were provided by the Yellow River Institute for Hydraulic Engineering and Water Resources Research. The researchers from that Institute calculated $S_{\text {dep,[S-L] }}$ for all flood events in the period 1950-1985 (Yellow River Institute for Hydraulic Engineering and Water Resources Research, 1987). During a flood event, the water surface slope varies with time. To reflect the average condition, the slope $(J)$ between Huayuankou and Lijin was used: $J=\left(H_{\text {Huayuankou }}-H_{\mathrm{Lijin}}\right) / L$, wherein $H_{\text {Huayuankou }}$ and $H_{\mathrm{Lijin}}$ are the water levels at $Q=3000 \mathrm{~m}^{3} / \mathrm{s}$ at Huayuankou and Lijin stations; $L$ is the distance between them. Because of lack of suspended sediment grain size data during the flood, the $D_{50}$ at Sanmenxia station was used for the flood event. The complete data used in the present study involve 141 events from the period 1956 to 1985 , for which $Q_{s}, D_{50}, Q$ and $J$ are available.

All hydrometric data used in the present study were provided by the Yellow River Conservancy Commission. Hydrometric measurements of water stage, discharge, suspended sediment concentration (SSC), grain size and SSL are conducted by the engineers and workers at the above-mentioned stations following the national standards issued by the Hydrological Bureau, Ministry of Water Conservancy and Electric Power (e.g., 1962, 1975). The procedures used for hydrological survey, sampling, and laboratory analyses at hydrometric stations in China are the same as those used internationally. A detailed introduction is contained in Yan (1984) and in the Sedimentation Commission of Chinese Society of Hydraulic Engineering (1992). Error analysis and accuracy tests have been carried out following the national standards to ensure data accuracy and reliability.

\section{Results}

\subsection{The scour-fill equilibrium in relation to Lane's relation}

According to the $\mathrm{SDR}_{\mathrm{FE}}$ of each event, the 141 flood events are classified as two types: those with net scour along the reach $\left(\mathrm{SDR}_{\mathrm{FE}}>1\right)$ and those with net fill $\left(\mathrm{SDR}_{\mathrm{FE}}<1\right)$. Considering Lane's relation, $Q_{S} D_{50}$ is plotted against $\gamma Q J$ in log coordinates (Fig. 2) where the scour and fill types are distinguished using different symbols. We see that mixing

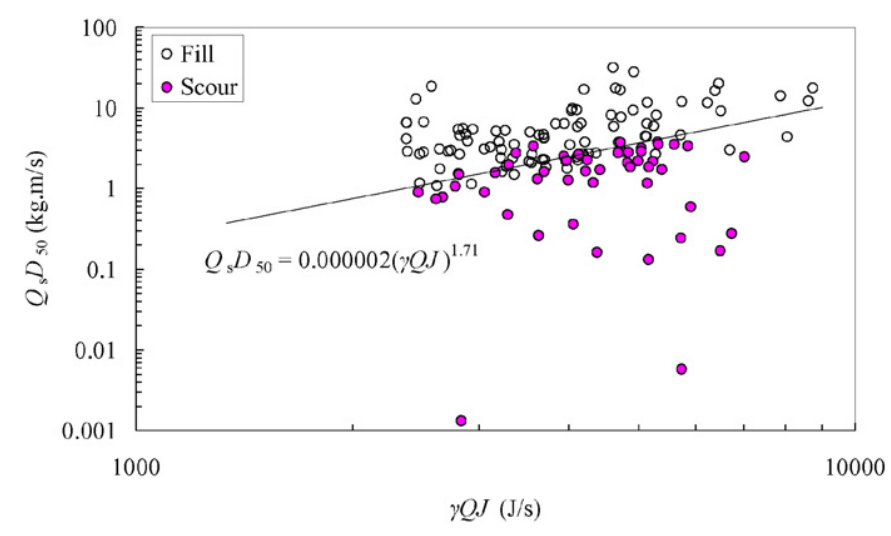

Fig. 2. $Q_{s} D_{50}$ plotted against $\gamma Q J$.

of the two types of points is few and that they can be well discriminated by

$Q_{s} D_{50}=0.000002(\gamma Q J)^{1.71}$

with the fill points located above the line and the scour points below. Considering the observed $\mathrm{SDR}_{\mathrm{FE}}$ and the predicted $\mathrm{SDR}_{\mathrm{FE}}$, the flood events with scour $\left(\mathrm{SDR}_{\mathrm{FE}}>1\right)$ and with fill $\left(\mathrm{SDR}_{\mathrm{FE}}<1\right)$ can be discriminated. Of the 92 events in fill-type, 76 (82.6\%) are correctly discriminated and $16(17.4 \%)$ are wrongly discriminated. Of the 49 events in scourtype, $41(83.7 \%)$ are correctly discriminated and $8(16.3 \%)$ are wrongly discriminated. Of all 141 events, 117 (83.0\%) are correctly discriminated and $24(17.0 \%)$ are wrongly discriminated.

\subsection{Regression of $S D R_{F E}$ with $\gamma Q J$ and $Q_{s} D_{50}$}

Multiple regression analysis has been performed between $\mathrm{SDR}_{\mathrm{FE}}$ and $\gamma Q J$ and $Q_{s} D_{50}$, based on data from 141 flood events. The correlation matrix for $\ln \left(\mathrm{SDR}_{\mathrm{FE}}\right), \ln (\gamma Q J)$, and $\ln \left(Q_{s} D_{50}\right)$ is shown in Table 1. The positive correlation between $\ln \left(\mathrm{SDR}_{\mathrm{FE}}\right)$ and $\ln (\gamma Q J)$ is significant with $p<0.01$, and the negative correlation between $\ln (\mathrm{SDR})$ and $\ln \left(Q_{\mathrm{s}} D_{50}\right)$ is significant with $p<0.0001$. To perform multiple regression, a prerquisite condition is that the influencing variables should be independent, namely, no correlation or very low correlation exists between them. The $R=0.117$ ( $p=0.169)$ between $\ln (\gamma Q J)$ and $\ln \left(Q_{s} D_{50}\right)$ indicates that it is reasonable to perform multiple regression. The regression equation is

$\mathrm{SDR}_{\mathrm{FE}}=0.00099(\gamma Q J)^{0.90}\left(Q_{S} D_{50}\right)^{-0.60}$.

The equation indicates that SDR $\mathrm{FE}_{\mathrm{F}}$ increases with $\gamma Q J$ and decreases with $Q_{s} D_{50}$. A comparison between the observed and predicted $S D R_{\mathrm{FE}}$ is shown in Fig. 3. The multiple correlation $R=0.935$ and $R^{2}=0.875$ indicates that $87.7 \%$ of the variation in $\ln \left(\mathrm{SDR}_{\mathrm{FE}}\right)$ can be explained by the variations in $\ln (\gamma Q J)$ and $\ln \left(Q_{s} D_{50}\right) . F(2,138)=482.50(p<0.000001)$, and standard error of estimate $\mathrm{SE}=0.3007$ (log unit).

The regression summary, the results of variance analysis and the partial correlation coefficients are listed in Tables 2, 3 and 4. The $t$ tests on the regression coefficients show that for $\ln (\gamma Q J), p=$ $1.38 \times 10^{-19}$ and for $\ln \left(Q_{s} D_{50}\right), p<0.000001$, indicating that the quality of Eq. (4) is high and acceptable. During the multiple regression

Table 1

Correlation matrix

\begin{tabular}{llcr}
\hline & $\ln (\gamma Q J)$ & $\ln \left(Q_{s} D_{50}\right)$ & $\ln \left(\mathrm{SDR}_{\mathrm{FE}}\right)$ \\
\hline $\ln (\gamma Q J)$ & 1.000 & 0.117 & 0.215 \\
$\ln \left(Q_{5} D_{50}\right)$ & 0.117 & 1.000 & -0.879 \\
$\ln (\mathrm{SDR})$ & 0.215 & -0.879 & 1.000 \\
\hline
\end{tabular}




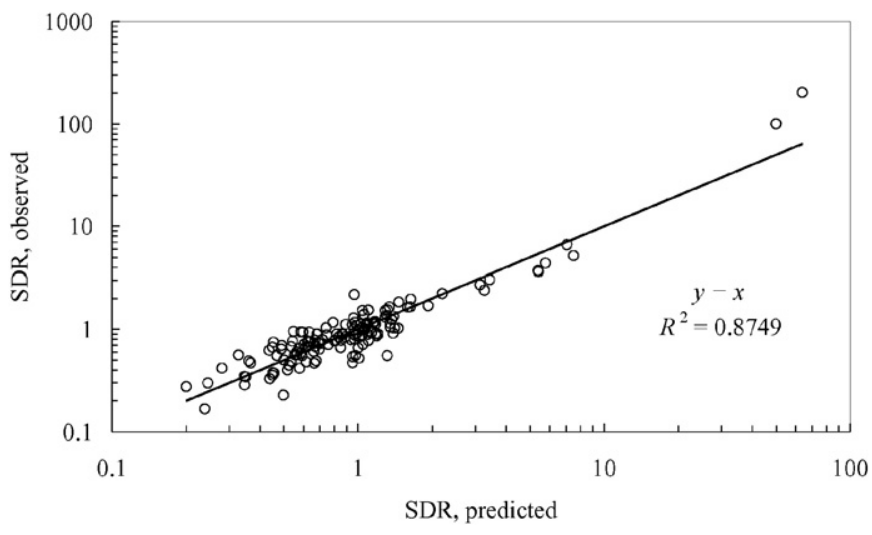

Fig. 3. Comparison between the observed and predicted SDR for Eq. (4).

analysis, the partial correlation coefficients and semipartial correlation coefficients were calculated (Table 4). The former is the correlation between the dependent variable and an influencing variable when the effect of other variable(s) is controlled, and the latter is the correlation between the dependent variable and an influencing variable after the influence of other variable(s) is partialled out. Thus, we estimated the contribution of the two influencing variables in terms of their semipartial correlation coefficients, assuming that the total contribution is $100 \%$. The results indicate that the contributions from $\ln (\gamma Q J)$ and $\ln \left(Q_{s} D_{50}\right)$ are $42 \%$ and $58 \%$, respectively. Thus, the contribution from $\ln \left(Q_{s} D_{50}\right)$ is larger than that from $\ln (\gamma Q J)$.

\subsection{Establishment of scour-fill threshold}

Based on Eq. (4) and letting SDR = 1, we have

$\mathrm{SDR}_{\mathrm{FE}}=0.00099(\gamma Q J)^{0.90}\left(Q_{S} D_{50}\right)^{-0.60}=1$

which may be rewritten as

$\left(Q_{S} D_{50}\right)^{0.60}=0.00099(\gamma Q J)^{0.90}$.

Raise the two sides to the power of $1 / 0.6$, then:

$Q_{S} D_{50}=0.00001(\gamma Q J)^{1.5}$.

Eq. (7) is an expression of the scour-fill threshold for the LYR. To show this more directly, we plotted $Q_{s} D_{50}$ against $(\gamma Q J)^{1.5}$ in Fig. 4, where the straight line $Q_{s} D_{50}=0.00001(\gamma Q J)^{1.5}$ is shown and the scour-type and the fill-type points are distinguished. Of the 92 events in fill-type, 82 (89.1\%) are correctly discriminated and 10 (10.9\%) are wrongly discriminated. Of the 49 events in scour-type, 38 (77.6\%) are correctly discriminated and 11 (22.4\%) are wrongly discriminated. Of all 141 events, 125 (88.7\%) are correctly discriminated and 16 (11.3\%) are wrongly discriminated.

We have made a comparison between the results of discrimination by Eq. (7) (Fig. 4) and that by Eq. (4) (Fig. 2). For all flood events, the percentage (88.6\%) of correct discrimination by formula (7) is higher than that (83.0\%) by Eq. (4). However, for the scour-type flood events,
Table 3

Result of variance analysis.

\begin{tabular}{llrcll}
\hline & Sums of squares & \multicolumn{1}{c}{ df } & Mean squares & F & $p$-level \\
\hline Regress. & 87.25889 & 2 & 43.62945 & 482.5024 & 0 \\
Residual & 12.47841 & 138 & 0.090423 & & \\
Total & 99.7373 & & & & \\
\hline
\end{tabular}

the percentage (83.7\%) of correct discrimination by Eq. (4) is higher than that (77.6\%) by Eq. (7); but for the fill-type flood events, the percentage (89.9\%) of correct discrimination by Eq. (7) is higher than that $(82.6 \%)$ by Eq. (4).

\subsection{On the physical meaning of the established scour-fill threshold}

As previously mentioned, the scour-fill threshold relation established in the present study is based on Lane's relation. Because Lane's relation is physically based, Eq. (7) also has some physical meaning. The sediment transport equilibrium is related to sediment transport mechanics. The flow strength for sediment transport may be expressed in three forms: flow velocity, flow shear stress, and stream power (Chien and Wan, 1983). Starting from general physical principles, Bagnold (1966) suggested that the energy expenditure due to bedload sediment transport can be expressed by specific stream power $(\omega)$ multiplied by an efficiency coefficient. Therefore, sediment transport rate is controlled by $\omega: \omega=\Omega / w=\gamma Q \mathrm{~J} / w$, where $w$ is channel width. Because sediment transport at whole width other than at unit width is considered in the present study, it is reasonable to express the flow strength using $\gamma Q J$. As $\gamma Q \mathrm{~J}$ in the right side of Eq. (7) is related to the flow strength in Bagnold's sediment transport formula, the scour-fill threshold relation (Eq. (7)) is physically based.

\subsection{Application of the results to water and sediment regime regulation}

As mentioned earlier, through regulation of the Xiaolangdi and other reservoirs in the Yellow River basin, we may design some optimal flowsediment combinations for floods deliberately released through the Xiaolangdi dam in order to transport sediment more effectively to the sea, and at the same time to reform the channel to increase its floodconveying capacity (Yellow River Institute of Hydraulic Engineering and Water Resources Research, 2010). Nine experimental floods were released from 2002 to 2009, and the results are shown in Table 5. Based on these data, we calculated $Q_{s} D_{50}$ and $\gamma Q J$ for each experimental flood event and then predicted the SDR $\mathrm{FE}_{\mathrm{F}}$ using Eq. (4). The observed $\mathrm{SDR}_{\mathrm{FE}}$ for each flood is shown in Table 5. Although some difference exists between the observed $\mathrm{SDR}_{\mathrm{FE}}$ and the predicted $\mathrm{SDR}_{\mathrm{FE}}$, all 9 points fall near the $y=x$ straight line (Fig. 5A) and below the scour-fill threshold line for the 141 flood events (Fig. 5B). Therefore, the approach and results of the present study are applicable for the design of flowsediment combinations for artificial floods. During the 9 experimental floods, scour occurred. This means that the two objectives have been realized, namely, the sediment released from the dam can be transported to the sea while the channel is scoured to increase its capacity. The amount of scour during the 9 artificial floods totaled $3.396 \times 10^{8} \mathrm{t}$, and from 2002 to 2009 the total amount of scour in the LYR was $11.92 \times 10^{8}$ t. Consequently, the bankfull discharge at Huayuankou

Table 2

Regression summary for influencing variables for Eq. (4).

\begin{tabular}{|c|c|c|c|c|c|c|}
\hline \multicolumn{7}{|c|}{$\mathrm{R}=0.93535406, \mathrm{R}^{2}=0.87488721$, Adjusted $\mathrm{R}^{2}=0.87307398$} \\
\hline \multicolumn{7}{|c|}{$\mathrm{F}(2,138)=482.50, \mathrm{p}<0.000001$, standard error of estimate: 0.30070} \\
\hline & BETA & St. Err. of BETA & B & St. Err. of B & $\mathrm{t}(138)$ & $p$-level \\
\hline Intercept & & & -6.91566 & 0.699808 & -9.88223 & $9.60 \times 10^{-18}$ \\
\hline $\ln (\gamma Q J)$ & 0.321514 & 0.030316 & 0.896992 & 0.08458 & 10.60524 & $1.38 \times 10^{-19}$ \\
\hline $\ln \left(Q_{s} D_{50}\right)$ & -0.91662 & 0.030316 & -0.59465 & 0.019668 & -30.2349 & 0 \\
\hline
\end{tabular}


Table 4

Partial correlation coefficients between dependent and influencing variables.

\begin{tabular}{|c|c|c|c|c|c|c|c|}
\hline & Beta in & Partial Correlation coefficient & Semipartial Correlation coefficient & Tolerance & $R^{2}$ & $t(138)$ & $p$-level \\
\hline $\ln (\gamma Q J)$ & 0.321514 & 0.670103 & 0.319324 & 0.986427 & 0.013573 & 10.60524 & $1.38 \times 10^{-19}$ \\
\hline $\ln \left(Q_{s} D_{50}\right)$ & -0.91662 & -0.93212 & -0.91037 & 0.986427 & 0.013573 & -30.2349 & 0 \\
\hline
\end{tabular}

station increased from 4100 to $6500 \mathrm{~m}^{3} / \mathrm{s}$, an increase of $58.5 \%$ (Yellow River Institute of Hydraulic Engineering and Water Resources Research, 2010; Chen et al., 2012).

Clearly, the errors between the observed and predicted $\mathrm{SDR}_{\mathrm{FE}}$ for the 9 experimental floods are large (Table 5). This may be explained by the different channel conditions between the period 2002-2009 and the period 1955-1985. After 1985, because of a significant decrease in streamflow, especially during the high-flow seasons, remarkable channel shrinkage was observed (Xu, 2002). However, after 2002, channel capacity began gradually to be restored. Channel shape is an important factor for sediment transport, especially for the Yellow River, because its width to depth ratio varies significantly downstream. When establishing a statistical sediment transport formula based on the LYR data, some researchers took the channel width to depth ratio into the equation as a variable (Chien and Zhou, 1965; Zhao et al., 1998). However, it was not considered when establishing Eq. (4) because data are not available. This problem should be resolved in the future.

\section{Discussion}

Many results related to scour-fill thresholds have been published. In fact, the critical flow condition under which bed sediment particles are set in motion is the scour threshold, and the critical flow condition under which sediment particles in motion stop moving is the fill threshold. Most results are related to coarse, noncohesive sediment and are based on experiments conducted in flumes, but the results related to fine sediment are few. The sediment of the LYR is fine, and it is difficult to observe the movement of sediment particles. Hence, most of the published results relate the scour-fill threshold to the condition: $S_{\text {dep }}=0$ or $\mathrm{SDR}=1$, within a given river reach. First, a regression equation of $S_{\mathrm{dep}}$ (or SDR) with suspended sediment concentration $(C)$ ( or $C / Q$ ) is established, then solved assuming $S_{\text {dep }}=0$ (or SDR $=1$ ). The resultant $C$ (or $C / Q$ ) is taken as the scour-fill threshold (e.g., Zhao, 1996; Zhao et al., 1998; Xu, 2014). These results are empirical, and no physical principles are considered. To improve these results, the present study starts from Lane's equilibrium relation and aims to establish some semitheoretical, semiempirical scour-fill threshold for the LYR. Using $\gamma Q J$ and $Q_{s} D_{50}$ to express the condition of sediment transport

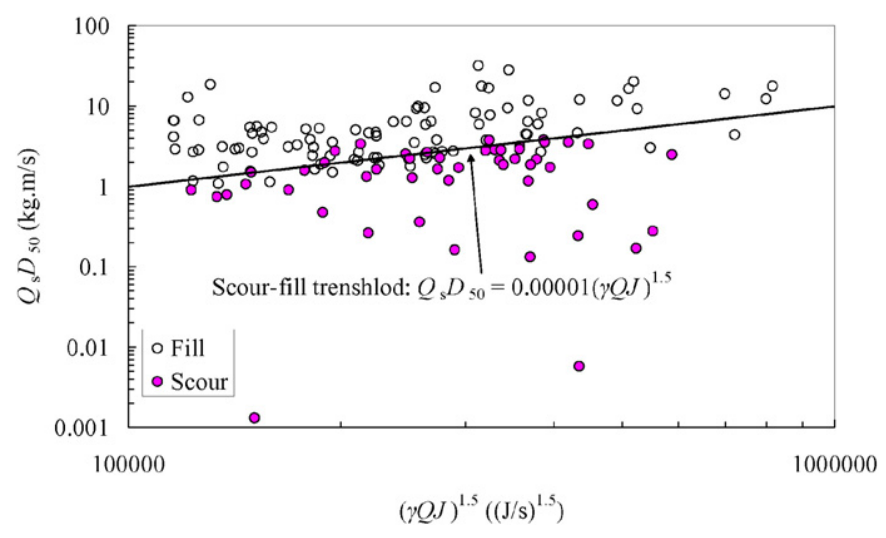

Fig. 4. $Q_{s} D_{50}$ platted against $(\gamma Q J)^{1.5}$. equilibrium, the results have some physical meaning and therefore, they are better than the previous purely empirical relations.

The results have some application implications in engineering practices in the LYR, which may be envisaged through a discussion based on the established threshold relation: $\mathrm{SDR}_{\mathrm{FE}}=0.00099$ $(\gamma Q J)^{0.90}\left(Q_{s} D_{50}\right)^{-0.60}=1$. In the most recent 20 years, its suspended channel has tended to become a two-level suspended channel (Yellow River Conservancy Commission, 2003; Gao et al., 2004; Hu and Zhang, 2006; Yang et al., 2006). Caused by the reduced water discharge, the channel has shrunk and a new, small-sized suspended channel has formed within the original, larger suspended channel (Fig. 6). Serious sedimentation is caused by a SDR much smaller than 1 . To reduce channel sedimentation and thereby to ease the serious situation presented by the two-level suspended channel, the SDR needs to be increased. In terms of Eq. (5), this objective may be realized in four ways: (i) increase water discharge; (ii) increase slope; (iii) reduce the sediment input to the LYR; and (iv) reduce the relatively coarse $(>0.05 \mathrm{~mm}$ ) fractions of sediment input to the LYR, by which to reduce $D_{50}$. The first option may be realized through reduction of water diversions by wider application of water-saving techniques, or through the reduction of flow at the Longyangxia dam during high-flow seasons. The third option may be realized through enhanced soil conservation practices (e.g., land terracing, tree- and grass-planting), through implementation of the strategy of "returning the cultivated steep slope-land to wood- or grass-land", and through the construction of sedimenttrapping check-dams and reservoirs in the drainage basin. The fourth option may be realized through enhanced erosion-controlling measures in the relatively coarse sediment producing areas in the drainage basin and through the trapping of more coarse sediment by the Xiaolangdi dam thereby reducing the grain size of sediment input to the LYR. Although realization of the second option is difficult because the average slope of the LYR may decrease slowly as the river mouth gradually extends into the sea, if the scheme of an engineered course change is realized, as suggested by some researchers (e.g., Ye et al., 1990), the length of the LYR would be significantly reduced, whereby the channel slope could be increased.

Although some progress has been achieved in the present study along the line of Lane's relation, more studies are needed in the future. In the present study, we take $Q_{s} D_{50}$ and $\gamma Q J$ as the influencing factors on the scour-fill thresholds. This is not sufficient, and channel morphology should also be considered because channel morphology is closely related to the scour-fill thresholds (Xu, 2004). At short timescales, e.g., during flood events, the channel morphology controls the difference in the scour-fill behavior in different segments. Because the channel width of the lower Yellow River varies downstream, the scour and fill behaviors also vary. Hence, during a flood, the pattern of scour and fill along the river is complicated. In a wide segment, the opportunities for fill would be greater than for scour, and vice versa. If data are available, these behaviors should be considered. However, because of lack of data, we are able to consider only the net scour or fill over the total length of the LYR [equal to the sum of individual scours (negative values) plus the sum of individual fills (positive values) over all segments], which can be calculated using Eq. (1). In the future, attention should be paid to the different scour and fill behaviors in different sub-reaches because the results are more useful to channel training and sediment management over subreach scales. Some channel morphologic variables should be taken into Eq. (7) so that the errors in Table 5 might be reduced. At longer timescales (e.g., decadal or longer), 
Table 5

Results for the 9 experimental floods.

Data in the right part of the table from Yellow River Institute of Hydraulic Engineering and Water Resources Research, 2010.

\begin{tabular}{|c|c|c|c|c|c|c|c|c|c|}
\hline No & Starting from & Duration (day) & Input $Q_{s}\left(10^{8} \mathrm{t}\right)$ & Input $Q_{w}\left(10^{8} \mathrm{~m}^{3}\right)$ & Output $Q_{s}\left(10^{8} t\right)$ & $\gamma Q J(W)$ & $Q_{s} D_{50}(\mathrm{~kg} \cdot \mathrm{m} / \mathrm{s})$ & $\mathrm{SDR}_{\mathrm{FE}}$, observed & $\mathrm{SDR}_{\mathrm{FE}}$, calculated \\
\hline 1 & $2002-7-4$ & 12 & 27.2 & 0.32 & 0.51 & 3073 & 0.370 & 1.59 & 2.41 \\
\hline 2 & $2003-9-6$ & 13 & 26.2 & 0.75 & 1.21 & 2734 & 0.534 & 1.61 & 1.74 \\
\hline 3 & 2004-6-19 & 25 & 46.6 & 0.04 & 0.7 & 2529 & 0.022 & 17.50 & 10.78 \\
\hline 4 & $2005-6-16$ & 16 & 40.0 & 0.02 & 0.61 & 3383 & 0.026 & 30.50 & 12.73 \\
\hline 5 & $2006-6-9$ & 21 & 57.6 & 0.08 & 0.65 & 3707 & 0.071 & 8.13 & 7.64 \\
\hline 6 & 2007-6-19 & 15 & 40.7 & 0.24 & 0.51 & 3661 & 0.204 & 2.13 & 4.02 \\
\hline 7 & $2007-7-29$ & 10 & 24.7 & 0.46 & 0.45 & 3332 & 0.586 & 0.98 & 1.97 \\
\hline 8 & 2008-6-19 & 20 & 43.9 & 0.46 & 0.6 & 2970 & 0.319 & 1.30 & 2.55 \\
\hline 9 & 2009-6-17 & 18 & 46.4 & 0.04 & 0.39 & 3497 & 0.118 & 9.75 & 5.33 \\
\hline
\end{tabular}
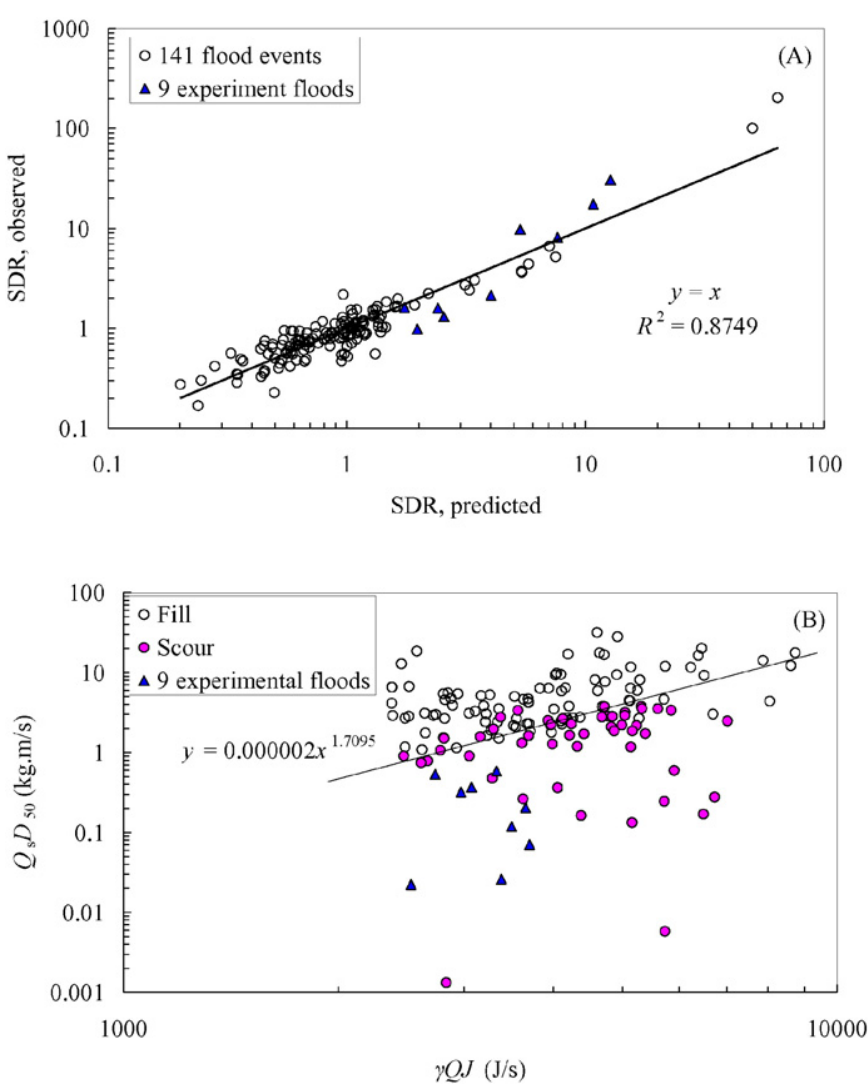

Fig. 5. Comparison of the 9 experimental floods with 141 floods. (A) Observed SDR $\mathrm{FE}_{\mathrm{FE}}$ versus predicted $\mathrm{SDR}_{\mathrm{FE}}$; (B) $Q_{s} D_{50}-\gamma Q J$ plot.

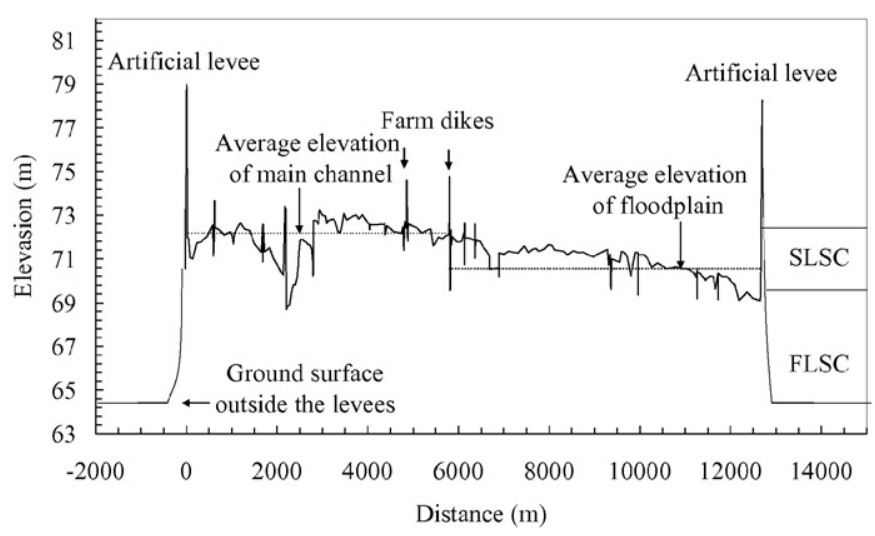

Fig. 6. A cross section showing the structure of two-level suspended channel. FLSC and SLSC are referred to as the first and the second level channels, respectively. channel morphology would also change when $Q_{s} D_{50}$ and $\gamma Q J$ change in a changing drainage-basin environment. Therefore, how the channel morphological variables respond to changing $Q_{s} D_{50}$ and $\gamma Q J$ should continue to be studied in the future.

\section{Conclusions}

River channel scour-fill threshold is an expression of scour-fill equilibrium, which may be understood as the balance between the river's sediment carrying capability and the sediment load imposed by the drainage basin. In the present study, the above capability-load relation is quantified by Lane's relation of $\gamma Q J-Q_{s} D_{50}$. On this basis, the scour-fill threshold for the lower Yellow River has been established. In $\log$ coordinates when $Q_{s} D_{50}$ is plotted against $\gamma Q J$, the flood events with scours are well distinguished from those with fills. Through regression analysis, the following equation is established: $\mathrm{SDR}_{\mathrm{FE}}=$ $0.00099(\gamma Q J)^{0.90}\left(Q_{s} D_{50}\right)^{-0.60}$. Setting the left side to 1 , the scour-fill threshold is established as: $Q_{s} D_{50}=0.00001(\gamma Q J)^{1.5}$. Of 141 flood events, $125(88.7 \%)$ are correctly discriminated by this threshold relation.

The approach put forward in the present study is useful for channel sedimentation control in the LYR. Since the Xiolangdi dam was built, a new strategy based on flow and sediment regulation has been put into practice. Artificial floods with optimal flow-sediment combinations are formed and released from the Xiaolangdi dam to transport sediment more effectively to the sea. The scour-fill threshold relation established in the present study can provide useful reference for the practice of flow-sediment regulation by the dams.

\section{Acknowledgments}

Financial support from the Natural Science Foundation of China (41330751) is gratefully acknowledged. All hydrometrical data were provided by the Yellow River Water Conservancy Commission. I am grateful to Dr. Bertrand Nivière and two other anonymous reviewers and the editor whose comments and suggestions were valuable for the improvement of the manuscript; to Dr. Mike Church who polished the English and made helpful modifications on the revised manuscript.

\section{References}

Bagnold, R.A., 1966. An approach to the sediment transport problem from general physics. U.S. Geological Survey Professional Paper No. 422-1 (31 pp.).

Binnie, S.A., Phillips, W.M., Summerfield, M.A., Fifield, L.K., 2007. Tectonic uplift, threshold hillslopes, and denudation rates in a developing mountain range. Geology 35 (8), 743-746.

Bull, W.B., 1979. Threshold of critical power in streams. Geol. Soc. Am. Bull. 90 (5), 453-464.

Chen, J.G., Zhou, W.H., Chen, Q., 2012. Channel re-establishment of the lower Yellow River in ten years operation of Xiaolangdi Reservoir. J. Hydraul. Eng. 43 (2), 127-135 (in Chinese).

Chien, N., Wan, Z.H., 1983. Mechanics of Sediment Movement. Science Press, Beijing (in Chinese).

Chien, N., Zhou, W.H., 1965. Channel Processes in the Lower Yellow River. Science Press, Beijing (in Chinese). 
Chien, N., Zhang, R., Zhou, Z.D., 1987. River Channel Processes. Science Press, Beijing (in Chinese).

Church, M., 2002. Geomorphic thresholds in riverine landscapes. Freshw. Biol. 47, 541-557.

Gao, J.Z., Hu, C.H., Chen, X.J., 2004. A preliminary study on alteration of watercourse and improvement of the "secondary perched river" in the lower Yellow River. J. China Inst. Water Resour. Hydropower Res. 2 (1), 8-18 (in Chinese).

Harnischmacher, S., 2007. Thresholds in small rivers? Hypotheses developed from fluvial morphological research in western Germany. Geomorphology 92 (3-4), 119-133.

Hassan, M.A., Church, M., Yan, Y.X., Xu, J.X., 2010. Spatial and temporal variation of in-reach suspended sediment dynamics along the mainstem of Changjiang (Yangtze River), China. Water Resour. Res. 46, W11551. http://dx.doi.org/10.1029/2010WR009228.

Hassan, M.A., Church, M., Yan, Y.X., Slaymaker, O., Xu, J.X., 2011. Suspended sediment balance for the mainstem of Changjiang (Yangtze River) in the period 1964-1985. Hydrol. Process. 25 (15), 2339-2353.

Hu, Y.S., Zhang, X.H., 2006. Brief discussion on the secondary perched river. J. Sediment. Res. 5, 1-9 (in Chinese).

Hydrological Bureau, Ministry of Water Conservancy and Electric Power, PRC, 1962. National Standards for Hydrological Survey. vols. 1-7. China Industry Press, Beijing (in Chinese).

Hydrological Bureau, Ministry of Water Conservancy and Electric Power, PRC, 1975. Handbook for Hydrolocical Survey. vols. 1-3. Water Conservancy and Electric Power Press, Beijing (in Chinese)

Kesel, R., Yodis, E., McCraw, D., 1992. An approximation of the sediment budget of the lower Mississippi River prior to major human modification. Earth Surf. Process. Landf. 17, 711-722.

Knighton, D., 1998. Fluvial Forms and Processes: A New Perspective. Arnold, London (376 pp.).

Lane, E.W., 1955. The importance of fluvial morphology in river hydraulic engineering. Proc. Am. Soc. Civ. Eng. 81 (754), 1-17.

Leopold, L.B., Wolman, M.G., Miller, J.P., 1964. Fluvial Processes in Geomorphology. W.H. Freeman and Co., San Francisco.

McLean, D.G., Church, M., 1999. Sediment transport along lower Fraser River: 2. Estimates based on the long term gravel budget. Water Resour. Res. 35 (8), 2549-2559.

Phillips, J.D., 2006. Evolutionary geomorphology: thresholds and nonlinearity in landform response to environmental change. Hydrol. Earth Syst. Sci. 10 (5), 731-742.

Schumm, S.A., 1977. The Fluvial System. John Wiley and Sons, New York.

Sedimentation Commission of Chinese Society of Hydraulic Engineering (Ed.), 1992. Handbook of Sedimentation. Publishing House for Environmental Sciences, Beijing (in Chinese).
Tucker, G.E., 2004. Drainage basin sensitivity to tectonic and climatic forcing: Implications of a stochastic model for the role of entrainment and erosion thresholds. Earth Surf. Process. Landf. 29 (2), 185-205.

Vandaele, K., Poesen, J., Govers, G., van Wesemael, B., 1996. Geomorphic threshold conditions for ephemeral gully incision. Geomorphology 16 (2), 161-173.

Walling, D.E., 1983. The sediment delivery problem. J. Hydrol. 65, 209-237.

$\mathrm{Xu}, \mathrm{J} . \mathrm{X}$., 2002. River sedimentation and channel adjustment of the lower Yellow River as influenced by low discharges and seasonal channel dry-ups. Geomorphology 43 (1-2), 151-164.

Xu, J.X., 2003. A study of sediment delivery by floods in the lower Yellow River, China. Hydrol. Sci. J. 48 (4), 553-566.

Xu, J.X., 2004. Double thresholds in scour-fill processes and some implications in channel adjustment. Geomorphology 57, 321-330.

Xu, J.X., 2005. Precipitation-vegetation coupling and its influence on erosion on the Loess Plateau, China. Catena 64, 103-116.

$\mathrm{Xu}, \mathrm{J} ., 2014$. The influence of dilution on downstream channel sedimentation in large rivers: the Yellow River, China. Earth Surf. Process. Landf. 39 (4), 450-462.

Yan, Y.S., 1984. An Introduction to Hydrometry. Water Conservancy and Electric Power Press, Beijing (in Chinese).

Yang, J.S., Xu, J.X., Liao, J.H., 2006. The process of secondary suspended channel in the lower Yellow River under different conditions of runoff and sediment load. Acta Geograph. Sin. 61 (1), 66-76 (in Chinese).

Ye, Q.C., 1994. Environmental Evolution and Laws of Water and Sediment Movement. Shandong Publishing House for Science and Technology, Jinan (in Chinese).

Ye, Q.C., Lu, Z.C., Yang, Y.F., Sun, Z.M., Zhang, Y.F., Su, X.M., Cao, Y.Z., 1990. River Geomorphology of the Lower Yellow River. Science Press, Beijing, pp. 242-251 (in Chinese)

Yellow River Conservancy Commission (Ed.), 2003. Formation Cause and Contro Measures of the Secondary Suspended Channel in the Lower Yellow River. Yellow River Conservancy Press, Zhengzhou (in Chinese).

Yellow River Institute of Hydraulic Engineering and Water Resources Research, 1987. Collections of Basic Data for the Channel Changes of the Lower Yellow River (Printed and Issued for Internal Use) (in Chinese).

Yellow River Institute of Hydraulic Engineering and Water Resources Research, 2010. Scour-fill process and the tendency in the lower Yellow River after the construction of the Xiaolangdi dam. Research Report No. ZX-2010-57, pp. 1-43 (in Chinese).

Zhao, W.L. (Ed.), 1996. Sediment of the Yellow River. Publishing House for Yellow River Water Conservancy, Zhengzhou (in Chinese).

Zhao, Y.A., Zhou, W.H., Fei, X.J., 1998. Basic Laws of Channel Process of the Lower Yellow River. Publishing House for Yellow River water Conservancy, Zhengzhou (in Chinese). 